\title{
BMJ Open Perceptions of chronically ill and healthy consumers about electronic personal health records: a comparative empirical investigation
}

\author{
Mihail Cocosila, ${ }^{1}$ Norm Archer $^{2}$
}

To cite: Cocosila $\mathrm{M}$, Archer N. Perceptions of chronically ill and healthy consumers about electronic personal health records: a comparative empirical investigation. BMJ Open 2014:4:e005304. doi:10.1136/bmjopen-2014005304

- Prepublication history and additional material is available online. To view please visit the journal (http://dx.doi.org/ 10.1136/bmjopen-2014005304).

Received 20 March 2014 Revised 29 June 2014 Accepted 1 July 2014

CrossMark

For numbered affiliations see end of article.

Correspondence to Dr Mihail Cocosila; mihailc@athabascau.ca

\section{ABSTRACT}

Objective: To develop a model of consumer perceptions of electronic personal health records (PHRs) and validate it in a comparative study between consumers who report having a chronic illness and those who report being well.

Materials and methods: A model of PHR use motivators and barriers was built and tested through a national survey across Canada. Data were collected from 800 individuals, 18 years or older. Half reported having a chronic illness or disability and half reported being well. Analyses were performed with structural equation modelling techniques.

Results: A total of 389 answers from chronically ill and 383 from well participants were collected. Perceived usefulness was the key explanation of the intention to use PHRs for both ill and well people (total effect of 0.601 and 0.565 , respectively) followed by security, privacy and trust in PHRs (total effect of 0.377 and 0.479 , respectively). Conversely, computer anxiety was perceived as a significant barrier (total effect of -0.327 for ill individuals and -0.212 for well individuals).

Discussion: The model proposed was appropriate in explaining key consumer positive and negative perceptions on electronic PHR use. We found little difference in perceptions of electronic PHRs between chronically ill and well individuals, although selfreporting their health status might have influenced the results.

Conclusions: To increase the adoption rate of electronic PHRs among both chronically ill and well consumers it is necessary to reinforce consumer perceptions of the usefulness of and trust in these eHealth technologies while mitigating their anxieties about computer use in general.

\section{OBJECTIVE}

Given the current shortage of medical resources available for managing the growing numbers of patients with chronic illnesses, it is becoming apparent that patient selfmanagement is a key to managing such

\section{Strengths and limitations of this study}

- This study developed an unbiased theoretical model of consumer perceptions of electronic personal health records (PHRs).

- The model was validated through empirical research comparing the perceptions of chronically ill and well consumers about electronic PHRs.

- The health condition of study participants was self-reported and not diagnosed by practitioners.

illnesses and improving health and quality of life. ${ }^{12}$ To manage this process effectively it is important for patients to maintain up-to-date and readily accessible health records. ${ }^{13}$ An online health self-management system that is grounded in the chronic care model ${ }^{4}$ and that utilises the patient's health record as a repository can support a system with selfmanagement functionalities for assisting in improved patient-centred care..$^{5-8}$

Health records maintained and accessible by individual consumers are referred to as personal health records (PHRs). Although they can be recorded and maintained in paper form, a fast emerging trend with the advent of digital data and the internet is to keep them in an electronic format. Therefore, we will assume throughout this paper that PHRs refer to electronic records on digital media. A PHR can be defined as "An electronic application through which individuals can access, manage and share their health information, and that of others for whom they are authorized, in a private, secure, and confidential environment." ${ }^{9}$ This is in contrast with EHR/EMRs (electronic health records/electronic medical records) which contain patient data gathered during the course of patient visits to healthcare providers, and are managed solely by healthcare providers or healthcare institutions. Also, 
most EHR/EMR data are based on acute care episodes ${ }^{10}$ since people are more likely to see their doctors when they have an acute problem.

An ideal form of a PHR is one that exchanges data freely, as authorised by the patient and the physician, between the physician's EHR/EMR and the patient's records, as needed. ${ }^{11}$

In theory, PHRs can be of great use to patients in the self-management of chronic diseases and disabilities, but there are significant obstacles to their sustainability, which refers to their adoption and continued use. Trials of eHealth implementations tend to be prone to participant dropouts (attrition). ${ }^{12}$ Reported attrition rates from the use of PHRs for health self-management vary widely, from as low as $3 \%$ for an interactive web-based intervention that included telephone counselling, to $65 \%$ in a smoking cessation programme, and to an enormous rate of $99 \%$ in a panic disorder self-help programme. ${ }^{13} 14$ Although factors affecting attrition tend to be complex, ${ }^{15}$ they must be addressed effectively if the benefits of self-management interventions are to be maximised.

The goal of better health may not be sufficient to motivate people to use PHRs, although there are techniques to predict in advance whether patients will adopt and continue with beneficial healthcare behaviours. ${ }^{16}$ If patient motivation to adopt PHR innovations were better understood, resulting reductions in attrition rates would lead to improved outcomes from health selfmanagement interventions.

Accordingly, the objective of this study is to determine the key motivators and barriers for individuals to adopt PHRs. As there are indications that people with serious chronic ailments and disabilities are more likely to be favourable to the adoption of PHRs than people who are well, ${ }^{9}$ we compared these two groups of people empirically to determine possible differences between adoption factors. Finally, we discuss the results and their significance to further sustainable development and implementation of PHRs, and consumer motivation to adopt and use them.

\section{BACKGROUND AND SIGNIFICANCE}

\section{Personal health records background}

Studies carried out in various parts of the world have indicated a great deal of public interest in PHRs. For instance, a major motivation for over $70 \%$ of US consumers is that they believe having access to PHRs would improve the quality of their healthcare ${ }^{17}$ although as yet there is no convincing evidence that this is the case. Field studies report that the greatest interest in PHRs is manifested by the chronically ill, frequent users of healthcare and caregivers for elderly parents. ${ }^{9} 18$ The same studies show that among American consumers saying they were not interested in using PHRs more than $55 \%$ indicated that worries about privacy and confidentiality affected their reluctance. Moreover, about
$90 \%$ of consumers surveyed felt that the provision of privacy, record access and user remedies would be significant factors affecting their agreement to use an online PHR service. ${ }^{17}$ Conversely, some barriers to maintaining and accessing PHRs include cost and loss of interest over time. $^{19}$

Through online and decision support for patientcentred care, changes in healthcare practice can often help to meet practice and patient goals. For example, research has demonstrated improvements in diabetes outcomes and chronic illness self-management when behavioural support is forthcoming from relevant technologies, improving dietary practices, physical activity and adherence to medication regimens. ${ }^{20}$ Other studies indicate that social activities are particularly important for older people, with health benefits that may include less chance of mortality, disability and depression, and better cognitive and health-related behaviours. ${ }^{21}$ Empirical studies have shown that relative advantage, ease of use, trialability, perceptions of privacy and security, age and computer experience were positive predictors of the value of PHRs for supporting communications with the doctor's office. $^{22}$ Therefore, it is important to understand the key motivators and deterrents for PHR adoption, with the target of improving the adoption rate and sustainability of these systems.

\section{Theoretical model and hypotheses}

In the following, we develop a theoretical model that takes into account the above considerations and test it for chronically ill and disabled consumers on the one hand and with consumers who feel that they are relatively healthy on the other hand, in order to compare their perceptions of PHRs. For this purpose we use a number of key constructs validated by previous research in information systems and healthcare, and propose hypotheses regarding their relationships, based on empirical findings and theoretical reasoning.

\section{Information seeking}

Although patients may prefer not to make all their own decisions about their healthcare, they do want to be kept informed. Reportedly, over $40 \%$ of patients with chronic conditions prefer to receive more information from their healthcare providers than they actually receive. ${ }^{23}$ It seems, therefore, that patients with higher information seeking preferences are more likely to feel that PHRs are useful in accessing information on their health status than those who do not. Therefore, we propose the following hypothesis:

H1: Consumers with higher information-seeking preferences will tend to believe that PHRs would be more useful.

\section{Personal information technology innovativeness}

This construct captures the willingness of an individual to try out an information technology, as it relates to the concept of technology acceptance. ${ }^{24}$ This indicates that 
people exhibiting high levels of information technology innovativeness will be more interested in accepting PHRs than those who do not. This leads to the hypothesis:

H2: Individuals with higher levels of IT innovativeness will exhibit higher levels of perceived usefulness for PHRs.

\section{Computer anxiety}

This construct expresses an individual's apprehension or fear when faced with the possibility of using a computer. ${ }^{25}$ Previous research has found a negative relationship between computer anxiety and perceived usefulness of new technology, as well as to intention to use a new technology. ${ }^{26}$ This results in the following propositions:

H3: Level of computer anxiety will be negatively related to the perceived usefulness of PHRs.

H4: Level of computer anxiety will be negatively related to the intention to use PHRs.

\section{Privacy, security and trust}

These concepts have been consistently found in large-scale studies to have an impact on consumer interest in online PHR adoption. ${ }^{28}$ While some surveys showed that two-thirds of adult consumers were concerned about security and privacy of their health data, ${ }^{17}$ other market studies found that consumers actually using a PHR did not worry too much about its privacy implications. ${ }^{29}$ The chronically and acutely ill and others who often require healthcare appear to have fewer concerns about privacy than do health professionals. ${ }^{30} 31$ Consequently, we propose the following hypotheses:
H5: Consumer perceptions of appropriate security and privacy of PHRs, and trust in PHR providers will positively affect their perceptions of PHR usefulness.

H6: Consumer perceptions of appropriate security and privacy of PHRs, and trust in PHR providers will positively affect their intention to adopt PHRs.

\section{Perceived usefulness}

This construct is a widely known and strong extrinsic motivator of technology use. It expresses "the degree to which a person believes that using a particular system would enhance his or her job performance." 32 In the case of PHR use, job performance (expectancy) would refer to being able to self-monitor accurately certain health parameters. Thus, it is logical to formulate the hypothesis below:

H7: Higher perceived usefulness for PHRs leads to a higher level of intention to adopt this technology.

The proposed constructs and their related hypotheses are shown in figure 1 in the form of a theoretical model of PHR adoption. The final endogenous construct of this model is behavioural intention to adopt PHRs that measures potential user intentions regarding this eHealth support tool.

\section{MATERIALS AND METHODS \\ Participant recruitment and data collection}

The theoretical model proposed by this study was tested with empirical data collected through an online survey of Canadian consumers. Both French and English versions were prepared and pre-tested with graduate students and practitioners in a Canadian university. The full-scale survey was approved by the Research Ethics

Figure 1 Theoretical model of personal health record adoption.

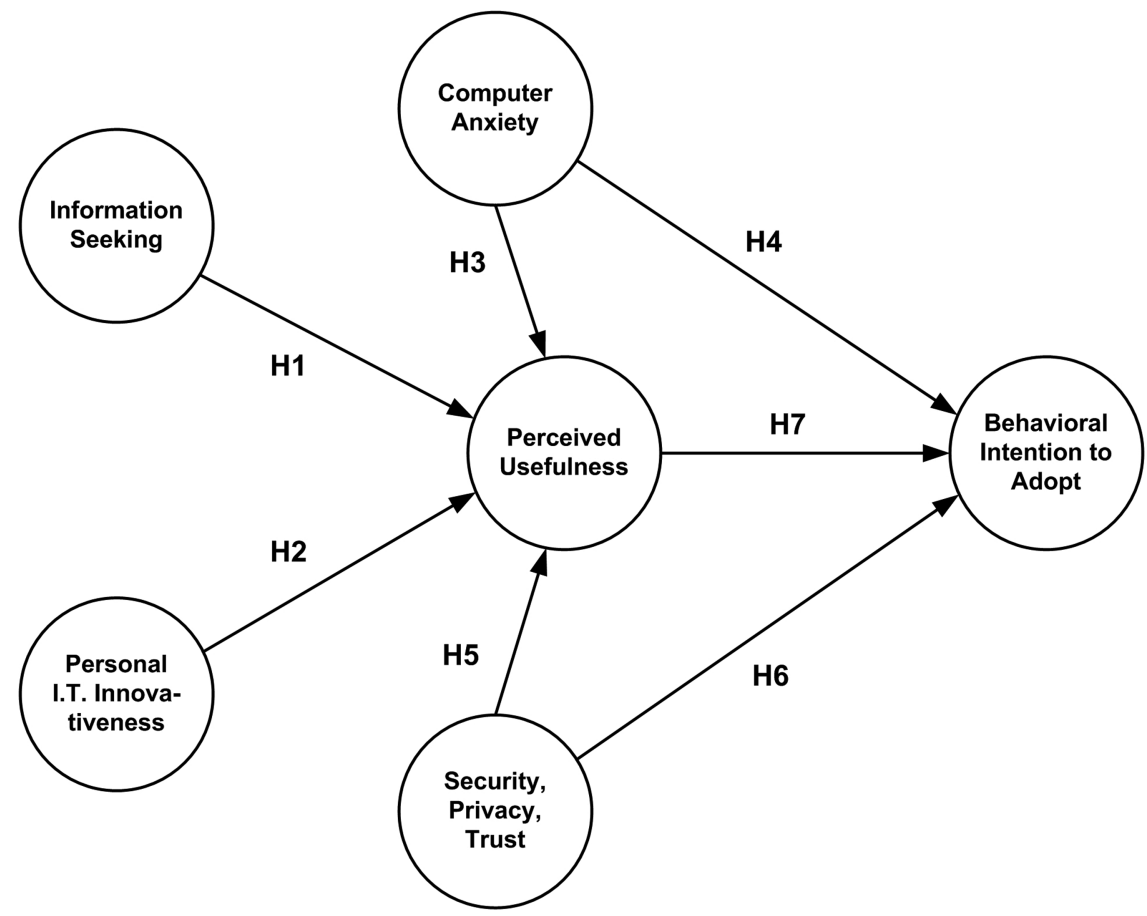


Board of the university and subsequently conducted with a Canadian internet panel of consumers through a market research company. There is no relationship between the researchers and this company, and the company was not allowed to analyse nor retain any copies of the data collected during the survey.

Participants were required to be at least 18 years old and willing to report their health condition. Participants were provided detailed descriptions of a chronic illness condition and of its typical degrees of severity: mild, moderate and severe. Eight hundred of the participants who had pre-registered with the market research company participated in the experiment: the sample was stratified to select exactly 400 who reported a chronic illness or disability at various levels of severity, and exactly 400 who did not report such a condition. These two strata will be indicated in the remainder of this study as 'Ill' and 'Well'.

All participants were presented a detailed description of an electronic patient health record system and then asked to answer an online questionnaire. The questions it contained were meant to measure the multi-item latent variables in the theoretical model described in figure 1 , together with relevant demographic characteristics of the participants surveyed. Most of the survey questions were adapted from those validated by previous research on healthcare (eg, information seeking) ${ }^{33}$ and information systems (eg, personal information technology innovativeness, computer anxiety, perceived usefulness and behavioural intention). ${ }^{24} 2732$ Measures for the only formative construct in the model, security, privacy and trust, although initially sourced from separate constructs in relevant information systems literature, were designed and validated as describing a single variable for this research. Measurement scales are included in online supplementary appendix A. All responses were collected on seven-point Likert scales ranging from strongly disagree (1) to strongly agree (7), with an additional not applicable option. Cases with more than $10 \%$ missing answers were deemed invalid and removed from the data analysis.

\section{Theoretical model evaluation}

As this research was intended mainly for exploratory purposes, data analysis was performed with partial least squares (PLS) due to the suitability of this structural equation modelling methodology for complex exploratory models, ${ }^{34}$ using formative indicators ${ }^{35}$ such as the security, privacy and trust construct used in this research. PLS analysis was carried out with the SmartPLS software tool $^{36}$ and included two successive model assessments: measurement tests (assessing the reliability and validity of the construct measures), followed by structural tests (evaluating the relationships between model constructs). ${ }^{37}$ Each analysis for the two subsamples (Ill and Well) was performed separately using the same model.

Use of the PLS tool for analysis determined the minimum study sample size. As the study involves a complex formative construct (ie, security, privacy and trust), the sample size should be at least 10 times the number of its indicators. ${ }^{38}$ Furthermore, sample size should account for possible high non-response rates or invalid cases in health-related studies. These considerations led to the target of 400 respondents in each of the two subsamples.

\section{Assessment of differences between ill and well individuals}

Results of theoretical model tests for the two subsamples were compared through differences in terms of the values of the path coefficients determined by PLS analysis. $^{38}$ The degree of difference was assessed with the t-statistic with $\mathrm{N} 1+\mathrm{N} 2-2$ degrees of freedom, ${ }^{39-41}$ where:

$$
\mathrm{t}=(\text { Path1-Path2) } /[\text { Spooled } \times \operatorname{sqrt}(1 / \mathrm{N} 1+1 / \mathrm{N} 2)]
$$

Here, Path1 and Path2 are the corresponding path coefficients in the model results and N1, N2 are the respective subsample sizes.

Spooled represents the pooled estimator for the variance and is calculated from:

$$
\begin{aligned}
& \text { Spooled }=\operatorname{sqrt}\{[\text { square of }(\mathrm{N} 1-1) /(\mathrm{N} 1+\mathrm{N} 2-2)] \\
& \times \text { square of } \mathrm{SE} 1+[\text { square of }(\mathrm{N} 2-1) /(\mathrm{N} 1+\mathrm{N} 2-2)]\} \\
& \times \text { square of SE} 2
\end{aligned}
$$

Here SE1 and SE2 are the standard errors of the corresponding path coefficients in the two subsample model results.

\section{RESULTS}

\section{Characteristics of study participants}

After removing the invalid cases, a total of 389 Ill cases and 383 Well cases remained and were used in further statistical analyses. Raw data analysed in this study were part of a larger project conducted in this setting. Table 1 shows comparative demographic characteristics, summarised for the two strata.

\section{Theoretical model evaluation}

An initial evaluation of the measurement model that comprised 22 items indicated the necessity of dropping 2 items when running it with the Ill data sample and 3 items when running it with the Well data sample, because of unsatisfactory significance and loading values of these items. After re-running SmartPLS for the remaining items, all reflective constructs for both samples displayed Cronbach's $\alpha$ and composite reliability values above 0.7 , average variance extracted (AVE) values above 0.5 , and item loadings above 0.7 , while the remaining items of the formative construct security, privacy and trust in PHR were significant and had loadings above 0.5. Thus, the measurement model was considered to have acceptable reliability and convergent validity for both subsamples. ${ }^{38} 4243$ 
Table 1 Participant characteristics

\begin{tabular}{lcc}
\hline & III participants & Well participants \\
\hline Sample size & 389 & 383 \\
Age (years, average) & 52.5 & 46.5 \\
Gender & & $221(57.7 \%)$ \\
Female & $248(63.7 \%)$ & $162(42.3 \%)$ \\
Male & $141(36.3 \%)$ & \\
Subject maintains up-to-date PHRs on paper & $132(34.0 \%)$ & $74(19.2 \%)$ \\
Yes & $257(66.0 \%)$ & $309(80.8 \%)$ \\
No & & \\
Subject maintains up-to-date electronic PHRs & $46(11.7 \%)$ & $22(5.8 \%)$ \\
Yes & $343(88.3 \%)$ & $361(94.2 \%)$ \\
No & 5.0 & 2.3 \\
Number of visits with a doctor during past 6 months (average) & 2.3 & 1.4 \\
Number of doctors seen during past 6 months (average) & 0.2 & 0.3 \\
Number of children 12 years old or younger for whom they & & \\
have main care responsibility at home (average) & $308(79.2 \%)$ & $81(21.2 \%)$ \\
Subject (or someone for whom they are responsible) has a chronic disease that requires continuing medical attention \\
Yes & $81(20.8 \%)$ & $302(78.8 \%)$ \\
No & $205(52.7 \%)$ & \\
Subject (or someone for whom they are responsible) has a disability that requires continuing care & $42(11.0 \%)$ \\
Yes & $184(47.3 \%)$ & $341(89.0 \%)$ \\
No & & $21(5.5 \%)$ \\
Subject is caring for elderly person(s) & $49(12.6 \%)$ & $362(94.5 \%)$ \\
Yes & $340(87.4 \%)$ & \\
No & & $247(64.4 \%)$ \\
Subject is interested in regularly maintaining records about health & $323(83.0 \%)$ & $136(35.6 \%)$ \\
Yes & $66(17.0 \%)$ & $222(58.0 \%)$ \\
No & $263(67.7 \%)$ & $111(29.0 \%)$ \\
Average amount of time spent using the internet at home daily (largest two categories out of $)$ & \\
31-60 min & $99(25.5 \%)$ & \\
$11-30$ min & & \\
PHR, personal health record. & & \\
\end{tabular}

A visual inspection of a matrix having the square root of AVEs on the diagonal and the correlations between all reflective constructs in the off diagonal cells showed diagonal numbers to be larger than all numbers on the corresponding rows and columns for both subsamples (table 2). This led to the conclusion that the model's reflective constructs had sufficient discriminant validity for both subsamples. ${ }^{37}$ Consequently, the measurement tests of the model for both subsamples indicated adequate reliability and construct validity for all measurement instruments, either adapted from previous research or developed by this study. This allowed the second step of the PLS process, which was to perform the structural analysis of the model.

Evaluation of the structural model involved running SmartPLS with a bootstrap of 200 re-samples. Results for path coefficients, their significance levels, and the values of $\mathrm{R}^{2}$ are compared in figure 2 for both subsamples.

SmartPLS results also provided the total effects of the factors in the theoretical model on behavioural

Table 2 Reflective construct correlations and square root of average variances extracted (AVEs) (III sample numbers off parentheses and Well sample numbers in parentheses)

\begin{tabular}{|c|c|c|c|c|c|}
\hline & $\begin{array}{l}\text { Computer } \\
\text { anxiety }\end{array}$ & $\begin{array}{l}\text { Behavioural } \\
\text { intention }\end{array}$ & $\begin{array}{l}\text { Information } \\
\text { seeking }\end{array}$ & $\begin{array}{l}\text { Perceived } \\
\text { usefulness }\end{array}$ & $\begin{array}{l}\text { Personal IT } \\
\text { innovativeness }\end{array}$ \\
\hline Computer anxiety & $0.89(0.91)$ & & & & \\
\hline Behavioural intention & $-0.51(-0.38)$ & $0.87(0.93)$ & & & \\
\hline Information seeking & $-0.13(-0.13)$ & $0.27(0.24)$ & $0.86(0.88)$ & & \\
\hline $\begin{array}{l}\text { Perceived } \\
\text { usefulness }\end{array}$ & $-0.47(-0.31)$ & $0.76(0.75)$ & $0.33(0.34)$ & $0.92(0.92)$ & \\
\hline $\begin{array}{l}\text { Personal IT } \\
\text { innovativeness }\end{array}$ & $-0.33(-0.17)$ & $0.46(0.38)$ & $0.07(0.03)$ & $0.39(0.42)$ & $0.92(0.94)$ \\
\hline
\end{tabular}


Figure 2 Path coefficients, significance levels and $R^{2}$ values for the personal health record adoption model (III subsample numbers above the line and Well subsample numbers below the line).

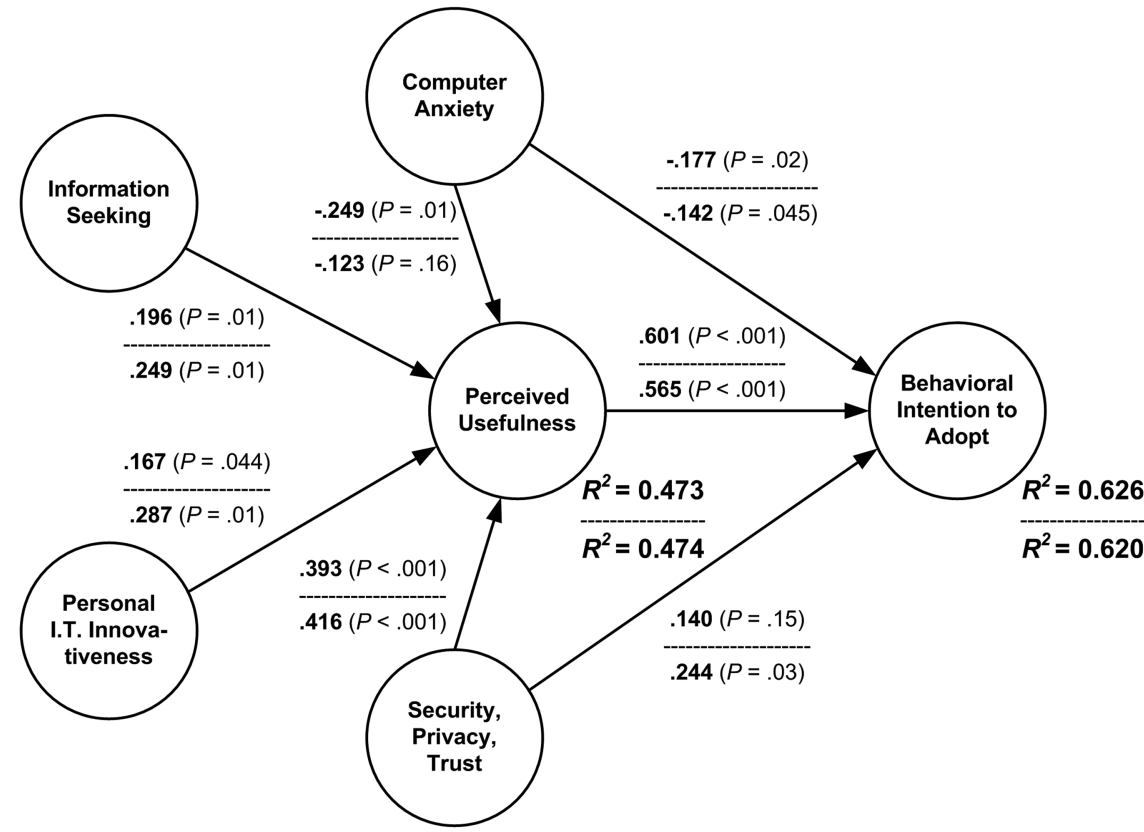

intention to use PHRs, for the two categories of participants (table 3 ).

All characteristics in table 1 were tested as potential control variables. In the case of the PHR Ill subsample the only influence came from the factor 'subject is interested in regularly maintaining records about health'. This factor influenced positively the perceived usefulness construct ( path coefficient of 0.234 at a $p=0.02$ significance level) and increased the variance explained by this construct from $\mathrm{R}^{2}=0.473$ to 0.521$)$. In the case of the PHR Well subsample the same interest in regularly maintaining records about health influenced positively the perceived usefulness construct (path coefficient of 0.171 at $\mathrm{a} p=0.04$ significance level and increased the variance explained from $\mathrm{R}^{2}=0.474$ to 0.499$)$. In addition for this subsample, the factor increased behavioural intention ( path coefficient of 0.154 at a $p=0.03$ significance level and increase of variance explained from $\mathrm{R}^{2}=0.620$ to 0.640$)$. So, the results for the control variable 'subject is interested in regularly maintaining records about health' played a significant role in both subsamples.

The self-reported degree of severity of the chronic illness or condition (ie, mild, moderate or severe) was tested as a possible control variable for the Ill subsample. No statistically significant effects on the theoretical model were noticed.

\section{Assessment of differences between ill and well individuals}

The results of the differences between the path coefficients of the model for the two subsamples are presented jointly in table 4 . No $p$ values were calculated since the lack of statistical significance, at a level of probability $\mathrm{p}<0.05$, of the difference between the results from the two subsamples (indicated by the low absolute $\mathrm{t}$ value of the difference) is very clear.

\section{DISCUSSION}

\section{Principal findings and comparison with prior work}

The objective of this study was to determine the key motivators for individuals to adopt electronic PHRs, through a theoretical behavioural model developed here. Furthermore, as previous research and theoretical reasoning indicated that people with chronic illnesses may be more likely to be favourable to the adoption of PHRs than people who are well, ${ }^{9}$ in our study we use the model we developed to compare two subsamples drawn in Canada from these two populations in order to assess

Table 3 Total effects and their significance levels on behavioural intention to adopt personal health records (PHRs)

\begin{tabular}{lcccc}
\hline & III sample & & \multicolumn{2}{c}{ Well sample } \\
\cline { 2 - 4 } Antecedent construct & Coefficient & p Value & & Coefficient \\
\hline Computer anxiety & -0.327 & $<0.001$ & -0.212 & 0.01 \\
Information seeking & 0.118 & 0.01 & 0.141 & 0.01 \\
Perceived usefulness & 0.601 & $<0.001$ & 0.565 & $<0.001$ \\
Personal IT innovativeness & 0.100 & 0.08 & 0.162 & 0.01 \\
Security, privacy and trust & 0.377 & $<0.001$ & 0.479 & $<0.001$ \\
\hline
\end{tabular}


Table 4 Statistical analysis of differences between III and Well consumer subsamples

\begin{tabular}{llll}
\hline Path & $\begin{array}{l}\text { III subsample path } \\
\text { coefficient }\end{array}$ & $\begin{array}{l}\text { Well subsample } \\
\text { path coefficient }\end{array}$ & $\begin{array}{l}\text { Absolute t value } \\
\text { of difference }\end{array}$ \\
\hline Computer anxiety $\rightarrow$ behavioural intention & -0.177 & -0.142 & 0.348 \\
Computer anxiety $\rightarrow$ perceived usefulness & -0.249 & -0.123 & 1.021 \\
Information seeking $\rightarrow$ perceived usefulness & 0.196 & 0.249 & 0.479 \\
Perceived usefulness $\rightarrow$ behavioural intention & 0.601 & 0.565 & 0.255 \\
Personal IT innovativeness $\rightarrow$ perceived usefulness & 0.167 & 0.287 & 0.982 \\
Security, privacy and trust $\rightarrow$ behavioural intention & 0.140 & 0.244 & 0.717 \\
Security, privacy and trust $\rightarrow$ perceived usefulness & 0.393 & 0.416 & 0.161 \\
\hline
\end{tabular}

empirically the possible behavioural differences and their determinants.

Our study (table 3 and figure 2) confirms largely the findings of research in information systems according to which perceived usefulness is the key explanation of the behavioural intention to use an information technology application. ${ }^{44}$ Therefore individuals, either chronically ill or well, would use PHRs only if they see the usefulness of these artefacts. This is concordant with findings on other empirical studies on PHRs that showed relative advantage $^{22}$ or perception of empowerment ${ }^{45}$ as key motivators of adoption.

As expected from previous research, ${ }^{17}$ the perception of security, privacy and trust in PHRs is a significant motivator for use in both categories of individuals surveyed. Table 3 shows that this factor is second in terms of total effect to Perceived Usefulness only, being significant at $\mathrm{p}<0.001$ for both subsamples. Interestingly, security, privacy and trust in PHRs has a non-significant direct influence on behavioural intention to use PHRs for the Ill subsample (coefficient $=0.140, \mathrm{p}=0.15$ ). This means security, privacy and trust mean less for ill people-the association of these features with usefulness is more important in the adoption equation. This is confirmed by previous research showing that benefits of access to medical records online may outweigh privacy risk perceptions. $^{46}$

Study results confirm that information seeking and personal IT innovativeness are motivators of PHR use for both categories of potential users while exerting their influence through perceived usefulness (table 3 and figure 2). However, the total effect of personal IT innovativeness over adoption intention is not significant for the Ill subsample, but it is for the Well subsample (table 3).

As hypothesised, computer anxiety is the only deterrent on PHR adoption in the theoretical model proposed by this study. It has a negative total influence significant at $\mathrm{p}<0.001$ for the Ill subsample and at $\mathrm{p}=0.01$ for the Well subsample (table 3).

All demographic characteristics measured and reported in table 1 were tested as control variables but had no effect for either sample with the exception of participant interest in regularly maintaining records about health. This factor was positive for both subsamples but more so for the Well one. Therefore, individual interest in self-monitoring health makes them better able to perceive PHR usefulness and to want to use these systems.

Overall, the original model proposed by this study to explain the adoption of PHRs had moderately high variance explained values for all the endogenous constructs, for both subsamples $\left(\mathrm{R}^{2}\right.$ of $0.473 / 0.474$ for perceived usefulness and $0.620 / 0.626$ for behavioural intention) and six of seven significant paths in both cases (figure 2 ). Therefore, from the statistical point of view, this model could be considered to be reasonably good. ${ }^{47}$

\section{Assessment of differences between ill and well individuals}

The key outcomes from the study of perceptions on PHRs of ill and well individuals in table 4 show that there were no statistically significant differences (at a level $\mathrm{p}<0.05$ ) between the two subsamples for any of the paths in figure 2. On the surface, these outcomes appear to contradict what we had expected-that people with chronic illnesses or disabilities are more interested in PHR adoption than are well people. We suspect that the differences are masked by the fact that many of the people in the Ill sample were, in fact, not seriously ill. The low rate of current PHR use in the both subsamples could be another explanation for the non-significant differences in perceptions between them. Findings from consumers, especially those with serious chronic illnesses, who had a considerable amount of experience with well-designed PHRs, might be more conclusive than the results from this comparative survey.

\section{Limitations}

As in virtually any empirical research, this study has some limitations. First, it is likely that the functionalities that accompany PHR systems would have a strong influence on their adoption. This aspect was not measured in this study. Second, the participants were all internet users, so it excluded many, particularly older, consumers who were not. In fact more than $60 \%$ of the survey participants overall claimed to use the internet for from 30 to $60 \mathrm{~min}$ per day. On the other hand, the proportion of internet and portable device users falls off rapidly with age beyond 65 years, ${ }^{48}$ especially for lower income seniors. Therefore, 
"those who can benefit the most from a PHR system may be the least able to use it." ${ }^{49}$ In addition to all these limitations, the most important for a comparative study such as this, participant health conditions were self-reported and not diagnosed by practitioners. Therefore, it is possible that the difference we found in overall perceptions between the two subsamples was not significant because the difference in participant self-reported health condition between the two subsamples was weak.

\section{CONCLUSIONS}

Despite the inherent limitations of an exploratory study, this research has the merit of investigating individual perceptions about electronic PHRs, using a rigorous theoretical approach that considers the perspectives of ill and well people separately. While remaining parsimonious, the theoretical model developed by this research has the merit of explaining a reasonably high per cent of the consumer intention to use electronic PHRs and thus could be a starting point for researchers examining more complex models of eHealth adoption.

According to the findings of this research, to maximise the chances of adoption for PHR support in selfmanagement initiatives, it appears necessary to enhance the motivators, especially the perceptions of usefulness as well as that of security, privacy and trust in PHRs, while mitigating anxieties associated with computer use. Developers and implementers of electronic PHRs should try to enhance the perceptions of positive factors among consumers, and focus on the benefits of using these systems in particular, since favourable factors are far more important than deterrents in the overall adoption equation.

A first exposure to PHRs did not reveal significantly different perceptions of this tool between individuals who reported having a chronic illness and those who reported being well. Therefore it appears that both categories of potential users should be addressed by promoters of PHRs in much the same way in terms of motivating and demotivating factors. However, caution is advised regarding assumptions of equivalence between individuals who report being chronically ill and those who have been diagnosed accordingly. Thus, future studies should attempt to survey chronically ill patients recruited through the healthcare system, after having a specified experience with self-managing their conditions with the aid of PHRs. A comparison of their perceptions of PHRs with those of well individuals would help to improve our understanding of how the adoption of PHRs could be increased overall.

\section{Author affiliations \\ ${ }^{1}$ Faculty of Business, Athabasca University, Athabasca, Alberta, Canada ${ }^{2}$ DeGroote School of Business, McMaster University, Hamilton, Ontario, Canada}

Contributors MC and NA made substantial contributions to conception and design, acquisition of the data or analysis and interpretation of the data; contributed to drafting the article or revising it critically for important intellectual content; and gave final approval of the version to be published.

Funding This research was funded by a grant from the Canadian Institutes of Health Research.

Competing interests None.

Patient consent Obtained.

Ethics approval Research Ethics Board of a Canadian University.

Provenance and peer review Not commissioned; externally peer reviewed.

Data sharing statement No additional data are available.

Open Access This is an Open Access article distributed in accordance with the Creative Commons Attribution Non Commercial (CC BY-NC 4.0) license, which permits others to distribute, remix, adapt, build upon this work noncommercially, and license their derivative works on different terms, provided the original work is properly cited and the use is non-commercial. See: http:// creativecommons.org/licenses/by-nc/4.0/

\section{REFERENCES}

1. Holman $\mathrm{H}$, Lorig K. Patient self-management: a key to effectiveness and efficiency in care of chronic disease. Public Health Rep 2004;119:239-43.

2. Warsi A, Wang PS, LaValley MP, et al. Self-management education programs in chronic disease. Arch Intern Med 2004;164:1641-9.

3. Weitzman ER, Kaci L, Mandl KD. Acceptability of a personally controlled health record in a community-based setting: implications for policy and design. J Med Internet Res 2009;11:e14. http://www. jmir.org/2009/2/e14/

4. Bodenheimer T, Wagner EH, Grumbach K. Improving chronic care for patients with chronic illness: the chronic care model, part 2. J Am Med Assoc 2002;16:1909-14.

5. Alphin S, Kjoller M, Davidsen M, et al. Self-reported ischemic heart disease: prevalence, sociodemographics, health behavior, health-care utilization, and quality of life. Open J Prev Med 2012;2:240-8.

6. Hess R, Bryce CL, Paone S, et al. Exploring challenges and potentials of personal health records in diabetes self-management: implementation and initial assessment. Telemed J E Health 2007;13:509-18.

7. Siminerio LM. The role of technology and the chronic care model $J$ Diabetes Sci Technol 2010;4:470-5.

8. Wiljer D, Urowitz S, Apatu E, et al. Patient accessible electronic health records: exploring recommendations for successful implementation strategies. J Med Internet Res 2008;10:e34. http:// www.jmir.org/2008/4/e34/

9. Markle Foundation. The personal health working group final report 2003. http://research.policyarchive.org/15473.pdf(accessed 27 Oct 2013). (Archived by WebCite at http://www.webcitation.org/ 6KhE3vwDS).

10. Tang PC, Ash JS, Bates DW, et al. Personal health records: definitions, benefits, and strategies for overcoming barriers to adoption. J Am Med Inform Assoc 2006;13:121-6.

11. Halamka JD, Mandl KD, Tang PC. Early experiences with personal health records. J Am Med Inform Assoc 2008;15:1-7.

12. Eysenbach G. The law of attrition. J Med Internet Res 2005;7:e11. http://www.jmir.org/2005/1/e11/

13. Farvolden $P$, Denisoff $E$, Selby $P$, et al. Usage and longitudinal effectiveness of a web-based self-help cognitive behavioral therapy program for panic disorder. J Med Internet Res 2005;7:e7. http://www.jmir.org/2005/1/e7/

14. Etter JF. Comparing the efficacy of two Internet-based, computer-tailored smoking cessation programs: a randomized trial. J Med Internet Res 2005;7:e2. http://www.jmir.org/2005/1/e2/

15. Fielding D, Duff A. Compliance with treatment protocols: interventions for children with chronic illness. Arch Dis Child 1999;80:196-200.

16. Shankar A, Conner M, Bodansky HJ. Can the theory of planned behaviour predict maintenance of a frequently repeated behaviour? Psychol Health Med 2007;12:213-24.

17. Markle Foundation. Americans overwhelmingly believe electronic personal health records could improve their health 2008. http://www. markle.org/sites/default/files/ResearchBrief-200806.pdf (accessed 27 Oct 2013). (Archived by WebCite at http://www.webcitation.org/ 67gKru0S3) 
18. Lafky DB, Horan TA. Prospective personal health record use among different user groups: results of a multi-wave study. Hawail International Conference on System Sciences, Proceedings of the 41st Annual, Hawaii, USA, 7-10 Jan 2008.

19. King DK, Toobert DJ, Portz JD, et al. What patients want: relevant health information technology for diabetes self-management. Health Technol 2012;2:147-57.

20. Benhamou PY. Improving diabetes management with electronic health records and patients' health records. Diabetes Metab 2011;37 (Suppl 4):S53-6.

21. Gilmour H. Social participation and the health and well-being of Canadian seniors. Health Rep 2012;23:23-32.

22. Emani S, Yamin CK, Peters E, et al. Patient perceptions of a personal health record: a test of the Diffusion of Innovation model. J Med Internet Res 2012;14:e150. http://www.jmir.org/2012/6/e150/

23. Strull WM, Lo B, Charles G. Do patients want to participate in medical decision making? J Am Med Assoc 1984;252:2990-4.

24. Agarwal R, Prasad J. A conceptual and operational definition of personal innovativeness in the domain of information technology. Info Syst Res 1998;9:204-15.

25. Simonson MR, Maurer M, Montag-Torardi M, et al. Development of a standardized test of computer literacy and a computer anxiety index. J Educ Comput Res 1987;3:231-47.

26. Igbaria M, Schiffman SJ, Wieckowski TJ. The respective roles of perceived usefulness and perceived fun in the acceptance of microcomputer technology. Behav Info Technol 1994; 13:349-61.

27. Venkatesh V, Morris MG, Davis GB, et al. User acceptance of information technology: Toward a unified view. MIS Q 2003;27:425-78.

28. Wen KY, Kreps G, Zhu F, et al. Consumers' perceptions about and use of the Internet for personal health records and health information exchange: analysis of the 2007 Health Information National Trends survey. J Med Internet Res 2010;12:e73. http://www.jmir.org/2010/4/e73/.

29. CHCF. Consumers and health information technology: a national survey 2010. http://www.chcf.org/publications/2010/04/ consumers-and-health-information-technology-a-national-survey (accessed27 Oct 2013). (Archived by WebCite at http://www. webcitation.org/6Ki6wprfO).

30. Hassol A, Walker JM, Kidder D, et al. Patient experiences and attitudes about access to a patient electronic health care record and linked Web messaging. J Am Med Inform Assoc 2004;11:505-13.

31. Walker J, Ahern DK, Le LX, et al. Insights for internists: "I want the computer to know who I am". J Gen Intern Med 2009;24:727-32.

32. Davis F. Perceived usefulness, perceived ease of use, and user acceptance of information technology. MIS Quarterly 1989;13:319-40.

33. Wilson EV, Lankton NK. Modeling patients' acceptance of provider-delivered e-health. J Am Med Inform Assoc 2004;11:241-8.

34. Bontis N, Crossan MM, Hulland J. Managing an organizational learning system by aligning stocks and flows. J Manag Stud 2002;39:437-69.
35. Thomas RD, Lu IRR, Cedzynski M. Partial least squares: a critical review and a potential alternative. 2005 Administrative Sciences Association of Canada Conference, Toronto, Ontario, Canada. http://citeseerx.ist.psu.edu/viewdoc/download?doi=10.1.1.86. 1719\&rep=rep1\&type=pdf (accessed 28 Oct 2013). (Archived by WebCite at http://www.webcitation.org/6Ki8UyHTh).

36. Ringle CM, Wende S, Will A. SmartPLS 2.0 (M3) Beta; 2005 http://www.smartpls.de/forum (accessed 28 Oct 2013). (Archived by WebCite at http://www webcitation org/5uZLmc5cJ).

37. Gefen D, Straub D. A practical guide to factorial validity using PLS-Graph: tutorial and annotated example. Commun Association Info Syst 2005;16:91-109.

38. Jarvenpaa SL, Shaw TR, Staples DS. Toward contextualized theories of trust: the role of trust in global virtual teams. Info Syst Res 2004;15:250-67.

39. Ahuja MK, Thatcher JB. Moving beyond intentions and toward the theory of trying: effects of work environment and gender on post-adoption information technology use. MIS Q 2005;29:427-59.

40. Archer N, Cocosila M. A comparison of physician pre-adoption and adoption views on Electronic Health Records in Canadian medical practices. J Med Internet Res 2011;13:e57. http://www.jmir.org/2011/ 3/e57/

41. Chin WW. Frequently asked questions-Partial Least Squares \& PLS-Graph; 2000. http://disc-nt.cba.uh.edu/chin/plsfaq/plsfaq.htm (accessed 28 Oct 2013). (Archived by WebCite at http://www. webcitation.org/5uZMSOxrz).

42. Bontis N. National intellectual capital index: a United Nations initiative for the Arab region. J Intellect Capital 2004;5:13-39.

43. Fornell C, Larcker DF. Evaluating structural equation models with unobservable variables and measurement error. J Mark Res 1981;18:39-50.

44. Venkatesh V, Speier C, Morris MG. User acceptance enablers in individual decision making about technology: toward an integrated model. Decision Sci 2002;33:297-316.

45. Agarwal R, Anderson C, Zarate J, et al. If we offer it, will they accept? Factors affecting patient use intentions of personal health records and secure messaging. J Med Internet Res 2013;15:e43. http://www.jmir.org/2013/2/e43/

46. Vodicka E, Mejilla R, Leveille SG, et al. Online access to doctors notes: patient concerns about privacy. J Med Internet Res 2013;15: e208. http://www.jmir.org/2013/9/e208/

47. Bontis N, Keow WCC, Richardson S. Intellectual capital and business performance in Malaysian industries. J Intellect Capital 2000;1:85-100.

48. Pew Internet. Mobile Health 2012. Pew Internet Research Cente 2012. http://pewinternet.org/Reports/2012/Mobile-Health.aspx (accessed 28 Oct 2013). (Archived by WebCite at http://www. webcitation.org/6Ki9MnKwz).

49. Kim EH, Stolyar A, Lober WB, et al. Challenges to using an electronic personal health record by a low-income elderly population. J Med Internet Res 2009;11:e44. http://www.jmir.org/2009/4/e44/ 